International Review of Research in Open and Distributed Learning Volume 19, Number 3

July -2018

\title{
Teaching Massive, Open, Online, Courses (MOOCs): Tales From the Front Line
}

Patrick R. Lowenthal, Chareen Snelson, and Ross Perkins

Boise State University

\begin{abstract}
Very little research has been conducted about what it is like to teach a MOOC. Given this, a mixed methods study, involving a survey of $186 \mathrm{MOOC}$ instructors and 15 follow-up interviews, was conducted to explore the motivation, experiences, and perceptions of instructors who have taught massive open online courses. Findings indicate that instructors were motivated to teach MOOCs for three main reasons: (1) interest and passion, (2) publicity and marketing, or (3) benefits and incentives. Most instructors had little online teaching experience prior to teaching their first MOOC, but were satisfied with the experience. The majority believed their own MOOC provided a high quality learning experience but thought that MOOCs overall might not be as good as face-to-face courses. Concerns were raised about the future of MOOCs for online learning.
\end{abstract}

Keywords: massive open online courses, MOOCs, online teaching, online learning, instructional design 


\section{Introduction}

Massive Online Open Courses (MOOCs) emerged from a vision of free public access to education through the use of very large, open enrollment, online courses (Fergusen, Sharples, \& Beale, 2015). The early history of MOOCs saw both excitement and confusion as educators and scholars tried to define, implement, and study this new approach to online education (Moe, 2015). MOOC research to date, though, has largely focused on completion rates (Anderson, Huttenlocher, Kleinberg, \& Leskovec, 2014; Jordan, 2014), student learning (Breslow et al., 2013), and/or student engagement (Anderson et al. 2014; Kizilcec, Piech, \& Schneider, 2013). While a focus on the student experience is entirely appropriate, seemingly little research has been conducted on the instructor experience. Several reviews of MOOC literature have been conducted to identify developing trends and directions for further research (Deng, Benckendorff, \& Gannaway, 2017; Ebben \& Murphy, 2014; Gasevic, Kovanovic, Joksimovic, \& Siemens, 2014; Veletsianos \& Shepherdson, 2016). These reviews highlight the gap in the literature about the instructor experience teaching a MOOC. For instance, Deng et al. (2017) reviewed 95 studies on MOOCs. When they found that some researchers had explored "MOOC instructors' motivations, challenges, and pedagogical preferences," they pointed out that "this literature is not as well developed as the research on students" (p. 179). Likewise, Veletsianos and Shepherdson (2016) conducted a review of the literature on MOOCs and found that only $8.2 \%$ of the 183 studies they reviewed focused on topics related to instructors and teaching; the studies within this category they explained focused primarily on "academics' awareness, perspectives of, and experience with MOOCs" (p. 214).

The research that has been conducted to date reveals some insights into what it is like to teach a MOOC and how instructors have responded to the experience. Evans and Myrick (2015), for instance, conducted a mixed-method study of professors who had taught a MOOC. They first surveyed 162 professors and then conducted follow-up interviews with five of the professors. Their results indicated that MOOC instructors were experienced faculty members, but had little prior online teaching experience. The instructors enjoyed having access to large numbers of students, but were also challenged by having many students with varying education and cultural backgrounds. They were also divided in their opinions about the purpose of MOOCs or whether students learned as well as they did in face-to-face courses.

Three additional studies involving qualitative interviews of MOOC instructors add more insights into the instructor experience. Haavind and Sistek-Chandler (2015) interviewed eight instructors who taught different kinds of MOOCs. Their findings reveal how instructors struggled with offering personalized and meaningful feedback to large numbers of learners. These instructors also saw themselves in a role that was less like an instructor and more like a "ship commander, leader, or director" (Haavind \& SistekChandler, 2015, p. 341). The instructors also described the open access and highly visible nature of the MOOC as a safety concern. In fact, one of the instructors described the experience of being stalked by a student who lived in the same city. In another study, Najafi, Rolheiser, Harrison, and Haklev (2015) interviewed eight University of Toronto instructors who had offered MOOCs through Coursera or edX. They found that the instructors were motivated to provide quality learning experiences to a broad range of students and that the instructors enjoyed contributing open educational resources. Nevertheless, there was a belief among some of the instructors that the MOOC did not provide the same quality of learning as university for-credit courses on the same topic. Another study involving interviews with 14 MOOC instructors was conducted by Zheng, Wisniewski, Rosson, and Carroll (2016). The results of this study 
suggest that the process of teaching a MOOC manifests through three stages including preparation of course curriculum, implementation of the course, and feedback to students. Instructors in this study were motivated to engage in the substantial work of teaching a MOOC due to the potential for global impact on students, professional growth, research opportunities, and enhanced name recognition. Zheng et al. (2016) identified five key challenges of teaching a MOOC. They found that instructors struggled with managing collaborative work, balancing the amount of time spent teaching the course, maintaining realistic expectations, dealing with critical students, and overall insufficient support. The results of these studies offer valuable insights, but the research is still limited.

Research suggests that there is a high-quality instructor behind every quality online course (Dunlap, 2005; Wilson, Ludwig-Hardman, Thornam, \& Dunlap, 2004). The typical MOOC, however, changes the role of the online instructor (Ross, Sinclair, Knox, Bayne, \& Macleod, 2014). As such, it is imperative to learn more about what it is like to teach a MOOC. For instance, do instructors actually enjoy teaching in this format? What have they learned from teaching massive online courses? What has teaching a MOOC taught them about their own pedagogy? If MOOCs are going to be a viable form of learning, and not simply a fad, then MOOC providers need to consider the perspectives and experiences of those who teach these large online courses. The purpose of this study was to better understand the motivation, experience, and perceptions of people who teach massive open online courses.

\section{Background of the Study}

There is not one single type of MOOC. Scholars have tried to categorize different types of MOOCs in order to differentiate some types of MOOCs from other types of MOOCs. For instance, scholars sometimes differentiate MOOCs as being cMOOCs, pMOOCs, or xMOOCs (Bonk, Lee, Reeves, \& Reynolds, 2017). cMOOCs are grounded in the theory of connectivism (Siemens, 2005); cMOOCs place the instructor in a co-learner role with students actively constructing and contributing knowledge through an interconnected network of social media, blogs, wikis, and other online communication tools. Another variant is called the pMOOC; the "p" in pMOOC stands for "project" or "problem." In pMOOCs, instructors serve as a guide while students collaborate to complete a project or address a problem. Then there is the xMOOC. The " $\mathrm{x}$ " in $x M O O C$ stands for eXtended (Downes, 2013). xMOOCs position the instructor at the center of the learning experience with an emphasis on didactic instruction through content and videos (Adams, Yin, Madriz, \& Mullen, 2014; Bonk et al., 2017). These are not the only types of MOOCs discussed in the literature (e.g., Ballester, 2016; Kim, 2016), but they illustrate how the instructor role shifts depending on the underlying format of the course.

Another shift in the instructor role occurs while designing a MOOC; the massive scale of a MOOC makes it impractical for instructors to work alone as they might when designing other courses. Research suggests that the design and development of MOOCs often requires a team of instructional designers, instructional developers, and subject-matter-experts (Hollands \& Tirthali, 2014b). MOOC instructors face multiple challenges, such as heavy workload, substantial time commitment, insufficient support, and lack of compensation, yet many who are faced with these challenges work through them for the opportunity to impact students on a global scale, develop professionally, engage in research, or build name recognition 
(Zheng et al., 2016). Additional research, though, is needed to better understand the motivation that drives instructors to take on the formidable task of teaching a MOOC, or continue to teach them after the first one.

We contend that the amount of teaching experience an instructor has-and in particular online teaching experience-is also an important factor when investigating instructors experiences teaching MOOCs. As previously mentioned, Evans and Myrick (2015) found that although many of the instructors in their sample were experienced faculty, most of them had little online teaching experience and were new to teaching MOOCs. Questions remain, though, how the experience of teaching a MOOC, which may be an instructor's initial foray into online education, impacts instructors overall teaching. For instance, how does teaching online in a large-scale course influence an instructor's course design and pedagogical decisions? Further research is needed to better understand the impact of MOOC instruction on overall teaching practice.

Finally, questions of instructional quality have been raised in the literature (Lowenthal \& Hodges, 2015; Margaryan, Bianco, \& Littlejohn, 2015). For example, Margaryan, Bianco, and Littlejohn (2015) identified low instructional design quality in the majority of the 76 randomly selected MOOCs they assessed. Lowenthal and Hodges (2015), though, found that MOOCs had the possibility of meeting similar course quality standards as other online courses. The literature, though, on the instructional quality of MOOCs is lacking an instructor's perspective. While interviews with MOOC instructors have yielded some initial insights into factors that could impact course quality-such as presentation skills, strong content, managerial skills, personalization, feedback, and student-centered interaction (Haavind \& SistekChandler, 2015), additional research is needed to better understand instructor's perspectives of the instructional quality of MOOCs.

\section{Method}

The goal of this mixed methods study (Onwuegbuzie \& Leech, 2005) was to investigate the motivations, experiences, and perceptions of MOOC instructors. More specifically, the following three groups of questions, derived from cross-cutting themes from prior studies, guided this research:

1. Motivation for Teaching MOOCs.

i. Why do people teach MOOCs?

ii. What do they expect to gain from teaching a MOOC?

2. MOOC Teaching Experience.

i. What have people learned from teaching a MOOC?

ii. How has teaching a MOOC impacted their instructional practice?

3. Perception of MOOC Educational Value. 
i. Do they think students learn as much in a MOOC as a traditional online course?

ii. What are their thoughts about the future of MOOCs?

This study used an explanatory sequential mixed methods research design with data collected during sequential quantitative and qualitative phases (Creswell \& Plano Clark, 2011). Data from the quantitative and qualitative phases of the study were merged during an analysis phase to combine them into a more informative whole where qualitative results helped to explain the quantitative findings (Creswell \& Plano Clark, 2011; Miles, Huberman, \& Saldana, 2014).

MOOC instructors were surveyed during the initial quantitative phase to collect as much information as possible related to the research questions. The sample was drawn from people who have taught a MOOC for Coursera or edX in the past. Similar to Evans and Myric (2015), we focused on Coursera and edX because these two platforms are among the largest and most well-established. At the time of this study, both companies listed past courses on their websites along with instructor information. The survey was sent to 767 instructors; 186 completed it to yield a $24.3 \%$ response rate. The survey was intentionally kept short to increase the likelihood that busy instructors would complete it. The survey contained a series of closed-response questions that asked about why they taught a MOOC, their past experience with online and MOOC instruction, and their perceptions of teaching and learning in MOOCs; it also included three open-ended questions focused on what they would do differently if they were to teach another MOOC, how teaching a MOOC has impacted their teaching, and if they had any additional comments. The quantitative results were downloaded and analyzed to generate descriptive statistics.

In the second qualitative phase of the study, a sample of instructors were purposefully selected from those who said they would teach another MOOC and those who would not. These instructors were invited to participate in follow-up interviews. Semi-structured interviews were conducted with 15 MOOC instructors who were asked the following questions:

1. What did you learn from your MOOC experience(s)?

2. What advice would you give a peer who is thinking about teaching a MOOC?

3. Can you explain how and why (or why not) student-to-teacher and student-to-student interaction was used or encouraged in the MOOC(s) you taught?

4. Do you think teaching a MOOC(s), helped your career? Why or why not?

5. What type of incentive (if any) were you provided to teach a MOOC?

6. Should colleges and universities offer college credit to participants for completing a MOOC? Why or why not?

7. Do you think MOOCs will be around in five years? Why or why not?

8. What should we have asked that we didn't? 
Transcripts of the recorded interviews and the open-ended survey questions were coded in NVivo 11 Plus for Windows using a multistage process involving a combination of structural, descriptive, and pattern coding (Saldana, 2016). Structural coding was used during an initial reading of the transcripts to organize responses by question while simultaneously becoming familiar with the data set as a whole. Structural coding was used to group responses from each question together for ease of review and comparison. Next, descriptive coding was used to label specific topics discussed in participant responses to each question. Descriptive coding helped to index the topics in the interview responses and label passages of qualitative data with short phrases that captured the essence of their meaning. Finally, pattern coding was used to group similar topics together. In other words, sections of qualitative data coded with similar labels during descriptive coding were grouped together under a higher-level node in NVivo (e.g., all nodes related to motivation). Consistency was promoted through repeated reading, checking, and rechecking of the coding following a process similar to the Constant Comparison approach from Grounded Theory (Glaser \& Strauss, 1967). The final step in the analysis was to link the coded qualitative data to the corresponding quantitative results to provide a deeper explanation of the overall findings (Creswell \& Plano Clark, 2011; Miles, Huberman, \& Saldana, 2014).

\section{Results}

In the following section, results are presented under headings that correspond to the three groups of research questions related to motivation, experience, and perceptions. Findings from quantitative and qualitative phases of the study are merged within each section to present a coherent and informative synthesis of the results. All quotes are from interview transcripts or open-ended survey responses.

\section{Motivation for Teaching MOOCs}

The survey contained a set of statements that asked participants to indicate their reasons for teaching a MOOC (see Table 1). Participants could select any or all statements that applied to them. The number of times each statement was selected is shown in decreasing order of magnitude in Table 1. The most frequently selected set of reason statements (see Table 1, Group 1) would suggest that MOOC instructors were motivated by interest or passion. The second group of statements aligned to publicity or marketing factors such as the push to use MOOCs for advertising and visibility (see Table 1, Group 2). The least selected group of reasons were related to benefits or incentives the instructor might receive when teaching a MOOC (see Table 1, Group 3). 
Table 1

Reasons for Teaching a MOOC

\section{Reason statements}

Number of times selected

\section{Group 1. Interest and Passion}

Interest in the format

$136(73.1 \%)$

Wanted to share knowledge I'm passionate about

$130(69.9 \%)$

Commitment to open education

$117(62.9 \%)$

Personal challenge

$114(61.3 \%)$

Thought I could create a good one

$93(50.0 \%)$

\section{Group 2. Publicity and Marketing}

Branding / advertising purposes

$42(22.6 \%)$

Departmental or institutional pressure

$40(21.5 \%)$

\section{Group 3. Benefits and Incentives}

A means to conduct research

Financial incentive

$19(10.2 \%)$

Received a course release

$14(7.5 \%)$

The follow-up interviews and open-ended survey responses provided additional insights into instructor motivation for teaching MOOCs. The link between quantitative and qualitative findings is illuminated through the organization of key insights from the coded interviews within the framework of the three groups of reason statements in Table 1.

Interest and passion. Reasons related to interest and passion were selected more often than other reasons for teaching MOOCs. These reasons emphasized intrinsic motivational factors such as passion, commitment, and the sheer challenge of creating a good MOOC that could be made available to a worldwide audience. Curiosity also played a role as noted by an instructor who stated that the "curiosity of whether it could be done, whether it could be done well, and whether it could be repeated" served as a driving motivating force. Some of the instructors specifically expressed how much they enjoyed the experience of teaching a MOOC and that their involvement was based on factors beyond external incentives. As one instructor pointed out, "I was not provided any incentive other than my own hope that it would extend an awareness of strategies for more effective charitable giving to a larger number of people." Similarly, another MOOC instructor stated that, "The main reason for doing it was to get the information out to teachers around the world who desperately need it." MOOCs served as a vehicle through which instructors could share information they were passionate about and to demonstrate new 
approaches for teaching. One instructor saw the MOOC as an opportunity to develop an "ideal" course in genetics that would be "accessible to people with a wide range of backgrounds that covers the content that we really ought to be teaching."

The quotes above indicate interest, passion, and a desire for widespread reach of the MOOCs these instructors were involved in. This finding is in agreement with prior research, which indicates that intrinsic motivational factors were important for MOOC instructors (Zheng et al., 2016).

Publicity and marketing. The use of MOOCs for advertising, visibility, or recruitment has served the goals of some institutions of higher education (Hollands \& Tirthali, 2014a). There was a perception among some of the participants that institutional interest in using MOOCs for advertising and increased visibility contributed to an agenda that pressed instructors to teach MOOCs. As one instructor noted, "For the universities, this is advertising more than anything else and that's why they're doing it and that's why they'll continue doing it." Another instructor explained that, "Our university has an agenda to develop online learning. The programs I manage already have minimum 50\% online delivery. A goal was for us to increase our visibility as individuals and to increase numbers applying for the programs."

Instructors also experience greater visibility for their work. One instructor noted that MOOCs are a "good way to publicize the work you're doing, and raise people's interest and awareness." In fact, there may be interweaving strands of institutional and personal branding as an instructor suggested when stating that, "For me, the MOOC was for some extent personal professional branding, and an exploration. It is to some extent an advertisement for our program."

Benefits and incentives. The third, and least selected, group of reasons for teaching a MOOC focused on benefits and incentives such as a means to conduct research, financial incentives, or course release time. The benefit for research is compelling given the large numbers of students to recruit as participants in a study. This was discussed by a MOOC instructor who stated that,

If we had 10,000 people who were willing to do kind of a small exercise, in this case it was on visual perception and game interacting media, we could run an experiment with far greater physical power than anyone had done before, so we did that.

In addition to the potential for research, other incentives included financial support, equipment, personnel, or a reduced teaching load. As one MOOC instructor explained, "The incentive they gave us was that they offered a salary and that they offered support. The salary was not very large, but it was money and for an academic, even small sums are important." Another instructor stated that, "Well, the school is helping a lot in the sense that I got some money to pay for some equipment that I needed to shoot the videos and so on. They also provided a nice recording studio." Financial and technical support was an essential consideration as noted by an instructor who said,

If I had to do the whole thing on my own without help I think it would have been a much higher barrier to entry. I got a couple of small grants, and I had a tremendous amount of IT support which to me is really critical. 
Unfortunately, incentives were not always available or they were insufficient. This might help to explain why benefits and incentives were the least commonly selected reasons for teaching a MOOC. As one person put it,

I would say that if you looked at the cost by time, I mean our cost was grossly undercompensated for it, just because it was above and beyond our normal duty. We didn't get any course relief. I would say it was the equivalent of maybe teaching a course and a half of normal, and we received maybe one summer month for it.

These findings are in agreement with other research that suggests the importance of offering sufficient resources and support personnel for MOOC instructors (Najafi et al., 2015) and how challenging it can be when resources or support personnel are missing or insufficient (Zheng et al., 2016).

\section{MOOC Teaching Experience}

Several questions from the survey asked participants about their experiences teaching online as well as teaching MOOCs. The majority of the instructors had little (9.7\%) to no (45.7\%) previous experience teaching online when they taught their first MOOC (see Table 2). Similar results were reported by Evans and Myrick (2015) in their study of MOOC instructors. The combined results from the present study and the previous study by Evans and Myrick (2015) suggest that many of those teaching MOOCs, at least for Coursera and edX, have very little experience teaching online prior to teaching their first MOOC. As one instructor explained, "My MOOC experience was my first foray into online instruction, which has become a big part of what I do since then. Mostly what I learned was, I learned a lot about teaching online.”

Table 2

Online Teaching Experience Prior to Teaching First MOOC

\begin{tabular}{cc}
\hline Level of experience & Number of instructors \\
\hline None & $85(45.7 \%)$ \\
Little & $18(9.7 \%)$ \\
Some & $35(18.8 \%)$ \\
A Lot & $48(25.8 \%)$ \\
\hline
\end{tabular}

Many of the instructors who participated in this study also had limited experience teaching MOOCs as indicated in Table 3. The majority (81.2\%) reported that, at the time of the survey, they had limited experience teaching MOOCs (e.g., one, two, or three courses), but a small percentage (4.3\%) had taught a MOOC seven or more times. Furthermore, their experiences teaching MOOCs were varied with some only teaching MOOCs on a set schedule (57.5\%), some only teaching MOOCs in a self-paced format (8.6\%), and others with experience teaching in both formats (33.9\%). 
Table 3

Prior Experience Teaching MOOCs

\begin{tabular}{ccc}
\hline Number of MOOCs taught & Number of instructors \\
\hline 2 & $64(34.4 \%)$ \\
3 & $56(30.1 \%)$ \\
4 & $31(16.7 \%)$ \\
5 & $7(3.8 \%)$ \\
6 & $7(3.8 \%)$ \\
$7+$ & $5(2.7 \%)$ \\
\hline
\end{tabular}

Note. Eight participants did not respond making total percentages less than 100.

The instructors who participated in the present study reported engagement with various types of MOOCrelated experiences as shown in Table 4. Findings reveal that $87.6 \%$ took part in designing a MOOC; 74.2\% served as the primary instructor of a MOOC; 61.3\% served as a Subject Matter Expert (SME), and less than a third had experience taking a MOOC as a learner.

Table 4

Experience With MOOCs

Types of experience

Designed (all or part of) a MOOC

Primary teacher/facilitator of a MOOC

Was involved as subject matter expert (e.g., in recorded lectures) in (all or part of) a MOOC

Served on a team teaching/facilitating a MOOC

Completed part of a MOOC as a learner

Completed all of a MOOC as a learner
Number of instructors
$163(87.6 \%)$
$138(74.2 \%)$
$114(61.3 \%)$
$91(48.9 \%)$
$55(29.6 \%)$
$25(13.4 \%)$

Instructor perspectives from interviews and open-ended survey questions helped to illuminate certain aspects of what they learned from their MOOC experiences and how their overall teaching was impacted as a result. 
MOOC course design. MOOC instructors identified the importance of establishing clear goals, careful planning, and good course design in advance since problems were quickly magnified with largescale enrollments. Similar concerns have been noted elsewhere (Haavind \& Sistek-Chandler, 2015; Zheng et al., 2016) about the potential for high visibility to lead to extreme criticism and reputation risk for MOOC instructors. An instructor reflected that

In a MOOC the students are very good at and very highly motivated to find the errors in your problems. Find the problems with your wording. This question isn't clear. This answer doesn't really make sense. I don't think this grading is fair. A lot of the time the students are actually right.

The downside to advanced planning and up-front course design required for a MOOC was that instructors felt that it was harder to adjust the course while it was in progress (something experienced online educators already have experience with). This was explained by an instructor who stated that,

In a MOOC, you can adjust but it takes a lot longer, so it's not like I can decide, you know what, this coming lecture I'm going to review the basic statistics that I realized people didn't get. You just have to anticipate that more.

In addition to overall course design, MOOC instructors noted certain challenges with course content development or the acquisition of resources. The vision for MOOCs as open access online courses for everyone means that free or open educational resources are an integral component, although this notion has been a contested one (Wiley, 2015). The ideal of using free materials becomes a challenge under certain conditions due to copyright issues and the nature of the course content. One instructor explained how this emerged as a problem:

My particular field is geology and this is a very visual field because we look at rocks, we look at minerals, we use various kinds of maps that we have to look at. It was a challenge for our team to put together this MOOC to find images, suitable images, that illustrated the concepts we were trying to teach and also were available but not copyright protected.

Other instructors were successful in acquiring materials through public domain and Creative Commons repositories, from private holdings where permission for use was granted, or they created their own materials as subject matter experts.

Video presentations were discussed as well. Instructors expressed concerns about the way videos were recorded and how they might be improved. Suggestions included offering variety in the videos beyond the talking head style, making videos shorter and more interactive, test-driving scripts with an audience, speaking slowly, being more relaxed and natural on-camera, having higher quality visuals or animations, and consideration of the global audience when creating the video content. A wide spectrum of approaches were adopted for video production, in agreement with findings from Najafi et al. (2015). Some instructors spent large amounts of time and effort to produce a highly polished product, while others went for a much simpler and basic approach. An elaborate video production process, described by a MOOC instructor, illuminates the potential for taking the process too far. 
What we did ended up taking a huge amount of time partly because we were going for the look of a Ken Burns special so I collected thousands of images to put in the videos. We also built a custom set for this thing. We had a three camera set up, one on a boom and all of this stuff. In short, we made it way harder than it really had to be.

In contrast, another instructor described using a much simpler approach to MOOC video production. This instructor explained that, "I didn't try and make it look like television. It's more like talking to a student in my office. So I found the editing was really simple. The actual preparing the lectures in terms of recording, was quite easy." A simpler approach may be suitable under some circumstances, but the desire to "get away from the talking head in recorded lectures" and integrate "different types of visual material" was expressed by some instructors.

Impact on instructional practice. The experience of teaching a MOOC had an impact on instructional practice in various ways including organization, assessment practices, consideration of cultural factors, quality control, and pedagogy. Some instructors believed the experience of teaching a MOOC simply made them better teachers by forcing them to work at large scale and in an unfamiliar medium where "the skills of making things more explicit, making things more carefully intelligible, being much more imagistic and image driven" helped their performance in the classroom. A more direct and tangible impact on instructional practice was noted through the use of MOOC course content, techniques, and strategies for other courses. Instructors described using their MOOCs for flipped or blended learning or they repurposed content from the MOOC to supplement other courses. As one instructor put it, "I have incorporated some of the MOOC lecture videos and MOOC-developed exercises into my traditional courses." The spillover from MOOCs to other courses taught by the instructors is a finding that has received very little attention in prior studies of MOOC instructors (Evans \& Myrick, 2015; Haavind \& Sistek-Chandler, 2015; Najafi et al., 2015; Zheng et al., 2016).

Table 5

Satisfaction With MOOC Teaching Experience

MOOC instructor ratings

\begin{tabular}{|c|c|c|c|c|c|c|c|}
\hline \multirow[b]{2}{*}{ Statements } & \\
\hline & $\mathbf{1}$ & 2 & 3 & 4 & 5 & $\boldsymbol{M}$ & SD \\
\hline I enjoy teaching MOOCs. & 4 & 8 & 17 & 84 & 73 & 4.15 & 0.91 \\
\hline I would teach a MOOC again. & 4 & 9 & 18 & 71 & 84 & 4.19 & 0.95 \\
\hline $\begin{array}{l}\text { Every teacher should teach a MOOC } \\
\text { at least once. }\end{array}$ & 30 & 50 & 66 & 25 & 15 & 2.70 & 1.14 \\
\hline $\begin{array}{l}\text { Teaching a MOOC is more work than } \\
\text { teaching a traditional asynchronous } \\
\text { online course. }{ }^{\mathrm{a}}\end{array}$ & 5 & 26 & 54 & 44 & 53 & 3.63 & 1.13 \\
\hline
\end{tabular}

Note. 1 = Strongly Disagree, 2 = Disagree, 3 = Neither Agree or Disagree, 4 = Agree, 5 = Strongly Agree. Numbers under each rating indicate a count of survey respondents. 
a Four participants did not respond to this question.

Overall satisfaction. The statements listed in Table 5 were rated by the MOOC instructors who completed the survey. This group of statements illuminate overall satisfaction instructors had with their MOOC teaching experiences. Mean ratings for the first two statements are similar for their enjoyment of teaching MOOCs $(M=4.15)$ and their willingness to teach another $(M=4.19)$. Reasons for these positive ratings are found in the qualitative data from interviews and open-ended survey responses. One instructor who was very positive about the experience put it this way:

I enjoyed the process of making it even though as I said it was a lot more work than I expected. I've enjoyed the process of teaching it even though my involvement in the actual day to day workings of the course has been minimal while it's been in progress. I have really enjoyed reading the discussion posts and the slides our community TAs and seeing the depths and the interests that the students can bring to a course like this. It's gratifying to know that there are people who are appreciating all the hard work that we've put into making this a good course.

Advice for new MOOC instructors. Despite the positive responses about teaching a MOOC, instructors had a less favorable opinion about the idea of every instructor teaching a MOOC at least once as indicated by the mean rating of 2.70 in Table 5 . Reasons for this finding were indicated by the advice instructors offered for those who might be considering teaching a MOOC. Suggestions included being clear about the purpose and reasons for teaching a MOOC, getting compensation and workload plans in place early in the process, obtaining adequate support (e.g., technical support, teaching assistants), resolving intellectual property issues, becoming familiar with the technology, gaining support from administration or other faculty members, and developing reasonable expectations for what can be accomplished on a massive scale with respect to assessment, instructional strategies, or interaction with students. Similar issues were previously identified as key challenges for MOOC instructors (Zheng et al., 2016).

\section{Perception of MOOC Educational Value}

The majority of instructors (83\%) believed that the MOOC they taught provided a high-quality learning experience (see Table 6). At the same time, almost $38 \%$ neither agreed nor disagreed that MOOCs are the future of online learning. While more than half (56\%) thought that MOOCs were as good as traditional asynchronous courses, $45 \%$ disagreed that MOOCs were as good as traditional face-to-face courses. 
Table 6

Perceptions of Educational Value

MOOC instructor ratings

\begin{tabular}{lccccccc}
\cline { 2 - 7 } Statements & $\mathbf{1}$ & $\mathbf{2}$ & $\mathbf{3}$ & $\mathbf{4}$ & $\mathbf{5}$ & $\boldsymbol{M}$ & SD \\
\hline $\begin{array}{l}\text { MOOC(s) I taught offered a high } \\
\text { quality learning experience. }\end{array}$ & 4 & 5 & 20 & 91 & 66 & 4.13 & 0.87 \\
$\begin{array}{l}\text { MOOCs can be as good as traditional } \\
\text { asynchronous online coursesa. }\end{array}$ & 4 & 22 & 51 & 67 & 39 & 3.63 & 1.02 \\
$\begin{array}{l}\text { MOOCs can be as good as traditional } \\
\text { face-to-face courses } \text {. }\end{array}$ & 23 & 62 & 55 & 27 & 16 & 2.73 & 1.13 \\
$\begin{array}{l}\text { Future of online learning is MOOCsc. } \\
\text { Mote. }\end{array}$ & 20 & 40 & 72 & 40 & 10 & 2.89 & 1.05 \\
\hline
\end{tabular}

Note. 1 = Strongly Disagree, 2 = Disagree, 3 = Neither Agree or Disagree, 4 = Agree, 5 = Strongly Agree. Numbers under each rating indicate a count of survey respondents.

a,b Three participants did not respond to this question. ${ }^{c}$ Four participants did not respond to this question.

Perceptions of MOOC quality. Course quality is a complex topic, but the large-scale of a MOOC introduces unique challenges that impact both the instructor and student experience. One obvious challenge is the difficulty of providing individual feedback to large numbers of students. In a MOOC, feedback can come from interaction with course quizzes, from TAs (teaching assistants), other students, or to a lesser degree from the instructor (Haavind \& Sistek-Chandler, 2015). Much of the person-toperson interaction occurs in discussion forums, which can quickly become overwhelming when there are thousands of participants. Participants in the present study described how they or their teaching assistants (when available) tried to interact with some of the students on the discussion forums, but they also tried strategies such as virtual office hours, weekly announcements, feedback to a few selected students, or by answering student questions in newly-created videos that were integrated as the course progressed.

Assessment of student work was another area made difficult by the scale of a MOOC. Typical assessment strategies included using quizzes or some form of peer assessment for open-ended student work such as writing or media projects. As one MOOC instructor noted, peer review was essential for assessing student writing given that they "had something like 60,00o learners enrolled by the end of the course." Yet, peer review was deemed somewhat limited since it depended on committed student volunteers. These findings are consistent with other studies that spoke to the assessment practices of MOOC instructors (Evans \& Myrick, 2015; Haavind \& Sistek-Chandler, 2015; Najafi et al., 2015).

Perceptions of the future of MOOCs. Instructor perceptions of the future of MOOCs have received little attention in previous research. Instructors in the present study offered several reasons for why they thought MOOCs would likely continue. Among these reasons were the attractiveness of learning 
on demand, the opportunity to reach large numbers of learners, and the ability to make a variety of courses available to a wide variety of people. One MOOC instructor put it this way,

There are folks out there who want to learn and MOOCs are free and open for them and available, then they'll be here 5 years, 10 years. I find that very exciting. I love the idea that there are individuals who aren't necessarily affiliated with a university and maybe already had university degrees themselves that are still so interested in learning about these various subjects that they're willing to take a course. I think that human motivation, personal motivation will keep MOOCs alive.

Nevertheless, respondents expressed concerns regarding the financial sustainability of MOOCs and the longevity of free versus for-profit MOOCs. One respondent suggested that certain types of MOOCs, such as those that are designed for professional certification, might have potential profitability as opposed to some other types of MOOCs. Several challenges were described including how to handle student fees, how to deal with transfer credits, and how to ensure that MOOCs are robust enough to be worthy of college credit. Instructors reported that these issues should be addressed to help ensure the longevity of MOOCs.

\section{Conclusion}

The findings from this study both support and expand on the small body of literature about MOOC instructor experiences and perspectives of teaching MOOCs. Questions related to motivation sought to explore why someone might take on the task of teaching an open large-scale online course. A key finding was that MOOC instructors have been primarily motivated for intrinsic reasons (e.g., worldwide impact on students) rather than extrinsic incentives (e.g., money or course release). However, the need for support is critical and not consistently available for MOOC instructors.

Instructors who participated in this study tended to have little prior experience teaching online prior to teaching their first MOOC, which suggests that they learned the basics of online teaching while teaching a large-enrollment course. The implications of this are that online pedagogy, or thoughts about what online teaching entails, may be shaped by their MOOC teaching experience. The findings support this, since instructors discussed how teaching a MOOC caused them to reflect on how they teach their face-to-face courses as well as how they might use course materials developed for their MOOCs with other courses in a synergistic fashion.

Perceptions of MOOC quality were primarily good when instructors were asked about their own courses. However, when asked about how the MOOCs compared to other online teaching and especially face-toface instruction, participants did not rate them as highly. Reasons for this can be attributed to the large scale of the MOOC and the challenges of providing feedback to students or individualized assessment.

This study was limited to instructors who were teaching on edX and Coursera platforms. Additional research could expand to multiple platforms and cover a greater variety of MOOC types. Longitudinal research may help to explore instructor perceptions over time as MOOCs continue to evolve and instructors gain more experience teaching in this format. 


\section{References}

Adams, C., Yin, Y., Vargas Madriz, L. F., \& Mullen, C. S. (2014). A phenomenology of learning large: The tutorial sphere of XMOOC video lectures. Distance Education, 35, 202-216. https://doi.org/10.1080/01587919.2014.917701

Anderson, A., Huttenlocher, D., Kleinberg, J., \& Leskovec, J. (2014). Engaging with massive online courses. In Proceedings of the 23rd international conference on World Wide Web (pp. 687-698). International World Wide Web Conferences Steering Committee. http://dx.doi.org/10.1145/2566486.2568042

Ballester, S. (2016, November 24). Massive Open Online Course (MOOCs) types. [Blog post]. Retrieved from http://project.ecolearning.eu/mooc-types/

Bonk, C. J., Lee. M. M., Reeves, T. C., \& Reynolds, T. H. (2017). The emergence and design of massive open online courses (MOOCs). In R. A. Reiser, \& J. V. Demsey (Eds.), Trends and issues in instructional design and technology (4th ed.; pp. 250-258). Boston, MA: Pearson.

Breslow, L., Pritchard, D. E., DeBoer, J., Stump, G. S., Ho, A. D., \& Seaton, D. T. (2013). Studying learning in the worldwide classroom: Research into edX's first MOOC. Research \& Practice in Assessment, 8(1), 13-25. Retrieved from http://www.rpajournal.com/studying-learning-in-the-worldwideclassroom-research-into-edxs-first-mooc/

Creswell, J. W., \& Plano Clark, V. L. (2011). Designing and conducting mixed methods research (2nd ed.). Thousand Oaks, CA: SAGE.

Deng, R., Benckendorff, P., \& Gannaway, D. (2017). Understanding learning and teaching in MOOCs from the perspectives of students and instructors: A review of the literature from 2014 to 2016. In K. C. Delgado, P. Jermann, M. Pérez-Sanagustín, D. Seaton, \& S. White (Eds.), Digital education: Out to the world and back to the campus, EMOOCs 2017. Lecture notes in computer science (Vol. 10254; pp. 176-181). New York, NY: Springer. doi:10.1007/978-3-319-59044-8_20

Downes, S. (2013). What the ' $x$ ' in ' $x M O O C^{\prime}$ 'stands for [G+ post]. Retrieved from https://plus.google.com/+StephenDownes/posts/LEwaKxL2MaM

Dunlap, J. (2005). Workload reduction in online courses: Getting some shuteye. Performance Improvement, 44(5), 18-25. http://dx.doi.org/10.1002/pfi.4140440507

Ebben, M., \& Murphy, J. S. (2014). Unpacking MOOC scholarly discourse: A review of nascent MOOC scholarship. Learning, Media and Technology, 39, 328-345. doi:10.1080/17439884.2013.878352

Evans, S., \& Myrick, J. G. (2015). How MOOC instructors view the pedagogy and purposes of massive open online courses. Distance Education, 36, 295-311. http://dx.doi.org10.1080/01587919.2015.1081736 
Fergusen, R., Sharples, M., \& Beale, R. (2015). MOOCs 2030: A future for massive online learning. In C. J. Bonk, M. M. Lee, T. C. Reeves, \& T. H. Reynolds (Eds.), MOOCs and open education around the world (pp. 315-326). New York, NY: Routledge.

Gasevic, D., Kovanovic, V., Joksimovic, S., \& Siemens, G. (2014). Where is research on massive open online courses headed? A data analysis of the MOOC research initiative. The International Review of Research in Open and Distributed Learning, 15(5), 134-176. Retrieved from http://www.irrodl.org/index.php/irrodl/article/view/1954

Glaser, B. G., \& Strauss, A. L. (1967). Discovery of grounded theory: Strategies for qualitative research. New York, NY: Taylor \& Francis.

Haavind, S., \& Sistek-Chandler, C. (2015). The emergent role of the MOOC instructor: A qualitative study of trends toward improving future practice. International Journal on E-Learning, 14, 331-350.

Hollands, F. M., \& Tirthali, D. (2014a). MOOCs: Expectations and reality. Center for Benefit-Cost Studies of Education, Teachers College, Columbia University. Retrieved from http://cbcse.org/wordpress/wpcontent/uploads/2014/05/MOOCs Expectations and Reality.pdf

Hollands, F. M., \& Tirthali, D. (2014b). Resource requirements and costs of developing and delivering MOOCs. The International Review of Research in Open and Distance Learning, 15(5), 113-133. https://doi.org/10.19173/irrodl.v15i5.1901

Jordan, K. (2014). Initial trends in enrolment and completion of massive open online courses. The International Review of Research in Open and Distributed Learning, 15(1). Retrieved from http://www.irrodl.org/index.php/irrodl/article/view/1651

Kim, S-W. (2016). MOOCs in higher education. In D. Cvetkovic (Ed.), Virtual learning, Ch.8 [Electronic book]. Retrieved from https://www.intechopen.com/books/virtual-learning/moocs-in-higher$\underline{\text { education }}$

Kizilcec, R. F., Piech, C., \& Schneider, E. (2013). Deconstructing disengagement: Analyzing learner subpopulations in massive open online courses. In Proceedings of the third international conference on learning analytics and knowledge (pp. 170-179). New York, NY: Association for Computing Machinery (ACM). https://doi.org/10.1145/2460296.2460330

Lowenthal, P. R., \& Hodges, C. (2015). In search of quality: Using quality matters to analyze the quality of massive, open, online courses (MOOCs). International Review of Research in Open and Distributed Learning, 16(5), 83-101. doi:10.19173/irrodl.v16i5.2348

Margaryan, A., Bianco, M., \& Littlejohn, A. (2015). Instructional quality of massive open online courses (MOOCs). Computers \& Education, 8o, 77-83. https://doi.org/10.1016/j.compedu.2014.08.005 
Miles, M. B., Huberman, A. M., \& Saldana, J. (2014). Qualitative data analysis: A methods sourcebook (3rd ed.). Thousand Oaks, CA: SAGE.

Moe, R. (2015). The brief \& expansive history (and future) of the MOOC: Why two divergent models share the same name. Current Issues in Emerging eLearning, 2(1). Retrieved from http://scholarworks.umb.edu/ciee/vol2/iss1/2/

Najafi, H., Rolheiser, C., Harrison, L., \& Haklev, S. (2015). University of Toronto instructors' experiences with developing MOOCs. International Review of Research in Open and Distributed Learning, 16(3), 233-255. https://doi.org/10.19173/irrodl.v16i3.2073

Onwuegbuzie, A. J., \& Leech, N. L. (2005). Taking the “Q” out of research: Teaching research methodology courses without the divide between quantitative and qualitative paradigms. Quality \& Quantity, 39, 267-296. https://doi.org/10.1007/s11135-004-1670-0

Ross, J., Sinclair, C., Knox, J., Bayne, S., \& Macleod, H. (2014). Teacher experiences and academic identity: The missing components of MOOC pedagogy. Journal of Online Learning and Teaching, 10, 57-69. Retrieved from http://jolt.merlot.org/voliono1/ross 0314.pdf

Saldana, J. (2016). The coding manual for qualitative researchers (3rd ed.). Thousand Oaks, CA: SAGE.

Siemens, G. (2005). Connectivism: A learning theory for the digital age. International Journal of Instructional Technology and Distance Learning, 2(1). Retrieved from http://www.itdl.org/journal/jan_05/articleo1.htm

Veletsianos, G., \& Shepherdson, P. (2016). A systematic analysis and synthesis of the empirical MOOC literature published in 2013-2015. International Review of Research in Open and Distance Learning, 17, 198-221. Retrieved from http://www.irrodl.org/index.php/irrodl/article/view/2448/3655

Wiley, D. (2015). The MOOC misstep and open education. In C. J. Bonk, M. M. Lee, T. C. Reeves, \& T. H. Reynolds, T. H. (Eds.), MOOCs and open education around the world (pp. 3-11). New York, NY: Routledge.

Wilson, B. G., Ludwig-Hardman, S., Thornam, C. L., \& Dunlap, J. (2004). Bounded community: Designing and facilitating learning communities in formal courses. The International Review of Research in Open and Distance Learning, 5(3). Retrieved from http://www.irrodl.org/index.php/irrodl/article/view/204/286

Zheng, S., Wisniewski, P., Rosson, M. B., \& Carroll, J. M. (2016). Ask the instructors: Motivations and challenges of teaching massive open online courses. In Proceedings of the 19th ACM Conference on Computer-Supported Cooperative Work \& Social Computing (pp. 206-221). New York, NY: Association for Computing Machinery (ACM). https://doi.org/10.1145/2818048.2820082 
Teaching Massive, Open, Online, Courses (MOOCs): Tales From the Front Line Lowenthal, Snelson, and Perkins

Athabasca

University

(c) (†) 